\title{
Bisantrene Hydrochloride
}

National Cancer Institute

\section{Source}

National Cancer Institute. Bisantrene Hydrochloride. NCI Thesaurus. Code C77218.

The hydrochloride salt of an anthracenyl bishydrazone with antineoplastic activity. Bisantrene intercalates with and disrupts the helical structure of DNA, resulting in DNA single-strand breaks, DNA-protein crosslinking, and inhibition of DNA replication. This agent is similar to doxorubicin in activity, but unlike doxorubicin, does not exhibit cardiotoxicity. 